Check for updates

Cite this: RSC Adv., 2019, 9, 39272

\title{
Magnetic solid-phase extraction of pyrethroid insecticides from tea infusions using ionic liquid- modified magnetic zeolitic imidazolate framework- 8 as an adsorbent
}

\author{
Xiaodong Huang, ${ }^{a}$ Yanan Liu, ${ }^{a}$ Huifang Liu, ${ }^{\text {ac }}$ Guangyang Liu, ${ }^{a}$ Xiaomin $\mathrm{Xu}{ }^{a}$ \\ Lingyun Li, ${ }^{a}$ Jun Lv, ${ }^{a}$ Haixiang Gao (D ${ }^{b}$ and Donghui Xu (D) *a
}

A simple, sensitive, and reliable magnetic solid-phase extraction (SPE) method coupled with GC-MS/MS for the effective analysis of four pyrethroids from tea infusions was developed. A magnetic adsorbent, named ionic liquid-modified magnetic zeolitic imidazolate framework-8 ( $\mathrm{Fe}_{3} \mathrm{O}_{4} / \mathrm{ZIF}-8 / \mathrm{IL}$ ), was prepared by immobilizing an ionic liquid (IL) on the surface of $\mathrm{Fe}_{3} \mathrm{O}_{4} / \mathrm{ZIF}-8$. The textures of $\mathrm{Fe}_{3} \mathrm{O}_{4} / \mathrm{ZIF}-8 / \mathrm{IL}$ were confirmed by material characterization, and the results suggested that the adsorbent possessed high magnetism (59.0 emu g ${ }^{-1}$ ), an adequate Brunauer-Emmett-Teller (BET) surface area $\left(104 \mathrm{~m}^{2} \mathrm{~g}^{-1}\right.$ ), and a large pore volume $\left(0.68 \mathrm{~cm}^{3} \mathrm{~g}^{-1}\right)$. To confirm the extraction performance of the prepared $\mathrm{Fe}_{3} \mathrm{O}_{4} / \mathrm{ZIF}$ $8 / \mathrm{LL}$, several experimental conditions affecting the extraction efficiency were investigated. Under the optimum conditions, the limits of determination (LODs) for the four pyrethroids were in the range of $0.0065-0.1017 \mu \mathrm{g} \mathrm{L}^{-1}(\mathrm{~S} / \mathrm{N}=3: 1)$ with an intra-day relative standard deviation (RSD) of $\leq 9.70 \%$ and inter-day RSD of $\leq 11.95 \%$. The linear ranges were $0.5-50 \mu \mathrm{g} \mathrm{L}^{-1}$ for bifenthrin and $0.5-500 \mu \mathrm{g} \mathrm{L}^{-1}$ for permethrin, cypermethrin, and flucythrinate, with determination coefficients higher than 0.999. Finally, the proposed technique was successfully applied for the determination of pyrethroids in real tea infusions. This work could be extended to other IL-modified metal-organic frameworks (MOFs) and to the development of different sample pretreatment techniques.

Received 20th September 2019 Accepted 1st October 2019

DOI: $10.1039 / c 9 r a 07617 d$

rsc.li/rsc-advances pyrethroids can enter into the human body through the food chain, creating a substantial health risk. ${ }^{5}$ Accordingly, several international organizations have set maximum residue levels for pyrethroids in tea, such as $0.2-30 \mathrm{mg} \mathrm{kg}^{-1}$ in the United States and $0.01-3 \mathrm{mg} \mathrm{kg}{ }^{-1}$ in the European Union. ${ }^{6}$ Therefore, the development of a sensitive and reliable analytical technique for monitoring pyrethroid insecticides in tea is of prime importance.

Sample pretreatment is a crucial component in the determination of pesticide residues in complicated matrices. Numerous sample preparation methods have been established for the analysis of pyrethroids, including liquid-liquid extraction, liquid-liquid microextraction, solid-phase extraction (SPE), solid-phase microextraction, and QuEChERS. ${ }^{7-11}$ Magnetic SPE (MSPE), as an alternative to SPE, has gained extensive recognition since its introduction in $1999 .{ }^{12}$ In this technique, a magnetic adsorbent is added to a sample solution and dispersed with the aid of a vortex, shaker, or sonicator. Then, an external magnetic field is used to facilitate efficient retrieval of the magnetic adsorbent. ${ }^{13}$ This extraction process is rapid and simple because of the magnetism of the magnetic adsorbent, which means that phase separation can be readily performed without tedious or time-consuming filtration or anstitute of Vegetables and Flowers, Chinese Academy of Agricultural Sciences, Key Laboratory of Vegetables Quality and Safety Control, Laboratory of Quality \& Safety Risk Assessment for Vegetable Products, Ministry of Agriculture and Rural Affairs of China, Beijing 100081, China. E-mail: xudonghui@caas.cn; Tel: +86 1082106963

${ }^{b}$ Department of Applied Chemistry, China Agricultural University, Beijing 100193, China

${ }^{c}$ School of Life Science and Food Engineering, Hebei Engineering University, Handan, 056000, China 
centrifugation steps. ${ }^{14}$ Recently, many magnetic adsorbents have been prepared for MSPE, such as magnetic molecularly imprinted polymers, magnetic carbon nanomaterials, and magnetic metal-organic frameworks (MOFs). ${ }^{15}$

Zeolitic imidazolate frameworks (ZIFs), a new subclass of MOFs with chemically stable zeolite-like frameworks, are usually formed from metal ions (e.g., $\mathrm{Zn}$ and $\mathrm{Co}$ ) and imidazolate organic linkers. ${ }^{16}$ ZIFs are microporous with high surface areas and uniform structured cavities, which endow them with remarkable physical, chemical, and thermal stabilities and excellent adsorption abilities. ${ }^{17,18}$ Among the different types of ZIFs, ZIF-8 has attracted widespread attention because of its high surface area, hierarchical porosity, easy preparation and costeffectiveness. Recently, ZIF-8 has been widely employed in gas storage, drug delivery, sensing, catalysis, and mixed matrix membranes. ${ }^{19-23}$ Furthermore, ZIF composites have been prepared by modification with different chemical reagents, such as chitosan, thiourea, polydopamine, and enzymes, to enhance their adsorption abilities and confer other novel properties. ${ }^{24-27}$

Ionic liquids (ILs), produced by associating large organic cations and organic anions, are a class of liquid molten salts with meting points at room temperature. ILs are regarded as an alternative to organic solvents because of their unique chemical and thermal stabilities, extremely low vapour pressures, nonflammability, and high selectivity. ${ }^{28}$ Accordingly, ILs have attracted widespread attention and have been widely used in catalysis, adsorption and separation, and modification. ${ }^{29-32}$ According to the literature, ILs can be used in an immobilized or non-immobilized form for separation. Modification of a support material with ILs can increase the extraction efficiency by introducing different interactions between the sorbent and target analyte, including ion-exchange, hydrophobic, electrostatic, hydrogen bonding, and $\pi-\pi$ interactions. $^{33,34}$ Some IL-modified ZIFs have been reported in recent years, and these ZIFs are attractive in many research fields, especially for sample pretreatment. ${ }^{35}$ To the best of our knowledge, no ZIF-8/IL-based composite adsorbent has been reported for the analysis of pyrethroids in a tea infusion.

A combination of magnetic ZIF-8 and hydrophobic IL could either promote the adsorption capacity of ZIF-8 for pyrethroids, or facilitate the applicability of IL in MSPE. Inspired by the above aspects, we sought to develop a simple, sensitive and reliable analytical technique using an IL-modified magnetic ZIF as an adsorbent for MSPE of pyrethroid insecticides from tea infusions. In this work, we prepared an IL-modified magnetic ZIF-8 nanocomposite via a simple synthesis by coating the IL on the surface of magnetic ZIF-8. Successful preparation of the magnetic nanocomposite was confirmed by material characterization. Furthermore, we optimized several experimental factors for the MSPE method. Finally, we applied the proposed method to the determination of four pyrethroids in tea infusions.

\section{Materials and methods}

\subsection{Materials}

The liquid standards (bifenthrin, permethrin, cypermethrin, and flucythrinate) were at a concentration of $1000 \mathrm{mg} \mathrm{L}^{-1}$ and were obtained from the Agro-Environmental Protection Institute, Ministry of Agriculture (Tianjin, China). A mixture of the four pyrethroids was prepared in methanol at a concentration of $100 \mathrm{mg} \mathrm{L}^{-1}$ and stored at $4{ }^{\circ} \mathrm{C}$ in darkness. Acetonitrile, ethyl acetate, acetone, methanol, and $n$-hexane were purchased from Sigma-Aldrich (St. Louis, MO, USA). All of the organic solvents were of HPLC grade. Analytical grade 2-methylimidazole, zinc sulfate heptahydrate, ferric chloride hexahydrate $\left(\mathrm{FeCl}_{3} \cdot 6 \mathrm{H}_{2} \mathrm{O}\right)$, ferrous chloride tetrahydrate $\left(\mathrm{FeCl}_{2} \cdot 4 \mathrm{H}_{2} \mathrm{O}\right)$, ammonium hydroxide (mass fraction 28\%), and thioglycolic acid were acquired from Aladdin Industrial Co. (Shanghai, China). Analytical grade ILs, including 1-hexyl-3-methylimidazolium hexafluorophosphate, 1-hexyl-3-methylimidazolium bis(trifluoromethanesulfonyl)imide, 1-octyl-3-methylimidazolium hexafluorophosphate, and 1-octyl-3-methylimidazolium bis(trifluoromethanesulfonyl)imide ([OMIM] $\mathrm{NTf}_{2}$ ), were purchased from Shanghai Yuanye Bio-Technology Co. (Shanghai, China). Ethanol, sodium chloride ( $\mathrm{NaCl})$, hydrochloric acid $(\mathrm{HCl})$ and sodium hydroxide $(\mathrm{NaOH})$ were of analytical grade and were obtained from Beijing Chemical Reagents Co. (Beijing, China).

\subsection{Preparation of magnetic ZIF-8/IL nanocomposites}

$\mathrm{Fe}_{3} \mathrm{O}_{4}$ nanoparticles were synthesized by a co-precipitation method as reported previously. ${ }^{36}$ In a typical procedure, $1.8 \mathrm{~g}$ of $\mathrm{FeCl}_{3} \cdot 6 \mathrm{H}_{2} \mathrm{O}$ and $0.8 \mathrm{~g}$ of $\mathrm{FeCl}_{2} \cdot 4 \mathrm{H}_{2} \mathrm{O}$ were dissolved in $240 \mathrm{~mL}$ of ultrapure water and stirred under a $\mathrm{N}_{2}$ atmosphere at $80^{\circ} \mathrm{C}$ for $30 \mathrm{~min}$. Then, ammonium hydroxide $(25 \%, 10 \mathrm{~mL})$ was added dropwise, and the mixture was stirred for another $30 \mathrm{~min}$. After that, precipitates were collected using an external magnetic field and washed three times each with ultrapure water and ethanol. Subsequently, the obtained precipitates were dried at $60{ }^{\circ} \mathrm{C}$ in a vacuum oven for $24 \mathrm{~h}$.

$\mathrm{Fe}_{3} \mathrm{O}_{4} / \mathrm{ZIF}-8$ was prepared using a modification of a previously reported method. ${ }^{37}$ Briefly, $0.1 \mathrm{~g}$ of $\mathrm{Fe}_{3} \mathrm{O}_{4}$ nanoparticles were added to $20 \mathrm{~mL}$ of an ethanol solution of thioglycolic acid $(20$ $\mathrm{mM}$ ) with shaking for $1 \mathrm{~h}$ at room temperature. The product was recovered by an external magnetic field and washed three times each with ultrapure water and ethanol. Afterwards, the obtained thioglycolic acid-functionalized $\mathrm{Fe}_{3} \mathrm{O}_{4}$ nanoparticles were redispersed in $240 \mathrm{~mL}$ of ultrapure water/ethanol $(1: 1, \mathrm{v} / \mathrm{v})$ and shaken for another $1.5 \mathrm{~h}$ at room temperature. Then, an ethanol solution $(20 \mathrm{~mL})$ of $0.84 \mathrm{~g}$ of 2-methylimidazole was added to the mixture, followed by stirring for $8 \mathrm{~h}$ at room temperature. Finally, the $\mathrm{Fe}_{3} \mathrm{O}_{4} / \mathrm{ZIF}-8$ product was retrieved by an external magnetic field and washed three times each with ultrapure water and ethanol. The final product was dried at $60^{\circ} \mathrm{C}$ in a vacuum oven for $24 \mathrm{~h}$.

The $\mathrm{Fe}_{3} \mathrm{O}_{4} / \mathrm{ZIF}-8 / \mathrm{IL}$ nanocomposite was prepared by immobilizing an IL on the surface of $\mathrm{Fe}_{3} \mathrm{O}_{4} / \mathrm{ZIF}-8$ via a simple direct immersion method based on the "physisorption" mechanism, and the entire process followed a modification of a previously reported method. ${ }^{38}$ Briefly, an IL ( $1 \mathrm{~g}$ ) was added to a centrifuge tube containing $6 \mathrm{~mL}$ of ethanol, followed by vortexing for $30 \mathrm{~s}$. After dispersion, different quantities of $\mathrm{Fe}_{3} \mathrm{O}_{4} / \mathrm{ZIF}-8$ (0.5, 0.6, $0.8,1,1.2$, and $1.5 \mathrm{~g}$ ) were transferred into the solution, which was kept under mechanical stirring for $30 \mathrm{~min}$ at room temperature. Then, the products were collected with an external 
magnet and washed three times with ultrapure water and ethanol. Finally, the prepared products were dried at $60{ }^{\circ} \mathrm{C}$ in a vacuum oven for $24 \mathrm{~h}$.

\subsection{Characterisation of magnetic ZIF-8/IL nanocomposites}

Transmission electron microscopy (TEM) and scanning electron microscopy (SEM) were conducted using a JEM-200CX microscope (JEOL, Tokyo, Japan) and a JSM-6300 microscope (JEOL, Tokyo, Japan), respectively. X-ray powder diffraction (XRD) measurements were performed on a D8 Advance diffractometer (Bruker, Karlsruhe, Germany). Fourier transform infrared (FT-IR) spectra were recorded on an FT-IR-8400 spectrometer (Shimadzu, Kyoto, Japan). Vibrating sample magnetometer measurements were conducted on a Versalab-7410 (Lake Shore, Columbus, USA). Nitrogen $\left(\mathrm{N}_{2}\right)$ adsorption and desorption isotherm measurements were performed on an ASAP2460 surface area and porosity analyser (Micromeritics, Norcross, USA).

A Shimadzu GC-2010 plus equipped with a Shimadzu TQ8040 triple-quadrupole MS (Shimadzu, Kyoto, Japan) was applied for the analyses. An Rtx-5Ms capillary column from RESTEK (Bellefonte, PA, USA, $30 \mathrm{~m} \times 0.25 \mathrm{~mm}$ i.d., $0.25 \mu \mathrm{m}$ film thickness) was used for separation. The injector temperature was $250{ }^{\circ} \mathrm{C}$. The carrier gas was helium at a constant flow rate of

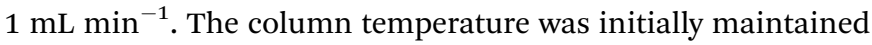
at $40{ }^{\circ} \mathrm{C}$ for $4 \mathrm{~min}$, then increased to $125{ }^{\circ} \mathrm{C}$ at $25{ }^{\circ} \mathrm{C} \mathrm{min}^{-1}$, increased to $300{ }^{\circ} \mathrm{C}$ at $10^{\circ} \mathrm{C} \mathrm{m^{-1 }}{ }^{-1}$, and held at $300{ }^{\circ} \mathrm{C}$ for $6 \mathrm{~min}$. The injection volume was $1.0 \mu \mathrm{L}$ in splitless mode. The specific multiple reaction monitoring (MRM) transitions for all four pyrethroids and other parameters are given in Table 1.

\subsection{Preparation of tea infusions}

Various types of tea, such as Pu-erh, Tieguanyin, Da Hong Pao, and Sichuan Maofeng, were purchased from a local market. Tea infusions were prepared according to an established method. ${ }^{39}$ Briefly, a tea sample $(2 \mathrm{~g})$ was infused in boiling water $(100 \mathrm{~mL})$ for $5 \mathrm{~min}$. After that, the infusion was transferred through a funnel to a glass beaker. Finally, the tea infusion was filtered through a $0.45 \mu \mathrm{m}$ polytetrafluoroethylene membrane filter and transferred to a dark-amber glass bottle. Method validation was performed by analysing ultrapure water and a blank tea infusion spiked with the standard mixture. All samples were stored at $4{ }^{\circ} \mathrm{C}$ before analysis.

\subsection{MSPE procedure}

The extraction of the four pyrethroids was studied using the obtained $\mathrm{Fe}_{3} \mathrm{O}_{4} / \mathrm{ZIF}-8 / \mathrm{IL}$ nanocomposite as a sorbent. First, $10 \mathrm{mg}$ of sorbent was dispersed into $10 \mathrm{~mL}$ of the sample solution ( $\mathrm{NaCl}, 5 \%$ mass fraction) in a $15 \mathrm{~mL}$ centrifuge tube and vortex-mixed for $1.5 \mathrm{~min}$ to perform the extraction. After that, the black sorbents were gathered by a magnet, and the clear supernatant was discarded. Subsequently, $0.8 \mathrm{~mL}$ of acetonitrile was added to elute the analytes from the magnetic sorbent under vortex mixing for $1 \mathrm{~min}$. After the magnetic sorbent was retrieved, the eluent was transferred to another $5 \mathrm{~mL}$ centrifuge tube. The same desorption experiment was conducted again. Finally, the desorption solvents were combined and evaporated to dryness under a gentle stream of $\mathrm{N}_{2}$ at $40{ }^{\circ} \mathrm{C}$. After that, the residue was redissolved in $0.5 \mathrm{~mL}$ of acetone, and a $1.0 \mu \mathrm{L}$ aliquot was injected into the GC-MS/MS system for analysis.

\section{Results and discussion}

\subsection{Characterization of $\mathrm{Fe}_{3} \mathrm{O}_{4} / \mathrm{ZIF}-8 / \mathrm{IL}$}

The morphology of $\mathrm{Fe}_{3} \mathrm{O}_{4} / \mathrm{ZIF}-8 / \mathrm{IL}$ was confirmed by SEM and TEM. Fig. 1A shows that the $\mathrm{Fe}_{3} \mathrm{O}_{4} / \mathrm{ZIF}-8 / \mathrm{IL}$ nanoparticles were in nanoscale, with slight aggregation. Fig. 1B shows a highly porous block-shaped structure for the $\mathrm{Fe}_{3} \mathrm{O}_{4} / \mathrm{ZIF}-8 / \mathrm{IL}$ nanocomposites. This porous structure could be good for the promotion of the ability of $\mathrm{Fe}_{3} \mathrm{O}_{4} / \mathrm{ZIF}-8 / \mathrm{IL}$ nanocomposites to adsorb pyrethroids.

FT-IR spectroscopy was used to study the surface properties of the prepared magnetic materials, including $\mathrm{Fe}_{3} \mathrm{O}_{4}, \mathrm{Fe}_{3} \mathrm{O}_{4} / \mathrm{ZIF}$ 8 , and $\mathrm{Fe}_{3} \mathrm{O}_{4} / \mathrm{ZIF}-8 / \mathrm{IL}^{40}{ }^{40}$ For all three synthetic magnetic materials (Fig. $1 \mathrm{C}$ ), the characteristic $\mathrm{Fe}-\mathrm{O}$ vibration at $558 \mathrm{~cm}^{-1}$ indicates the successful incorporation of $\mathrm{Fe}_{3} \mathrm{O}_{4}$ into the $\mathrm{ZIF}-8$ nanocomposites. ${ }^{41}$ The peaks between 993 and $1421 \mathrm{~cm}^{-1}$ were assigned to the $\mathrm{Zn}-\mathrm{N}$ stretching vibration of ZIF-8. The vibration of the $\mathrm{C}-\mathrm{H}$ bond of the alkyl groups at the nitrogen atoms of the imidazole ring can be observed from the bands at 878,2825 and $2960 \mathrm{~cm}^{-1}$. The peaks at 1059 and $1138 \mathrm{~cm}^{-1}$ can be attributed to the asymmetric and symmetric stretching of $\mathrm{O}=\mathrm{S}-\mathrm{O}^{-}$, whereas those at 1197 and $1350 \mathrm{~cm}^{-1}$ were assigned to the asymmetric and symmetric stretching of $\mathrm{O}=\mathrm{S}=\mathrm{O} \cdot{ }^{39}$ These results may indicate the feature structure of IL.

Table 1 Acquisition and chromatographic parameters for four pyrethroids

\begin{tabular}{llllc}
\hline Triazoles & $t_{\mathrm{R}}(\mathrm{min})$ & MRM1 $(\mathrm{m} / \mathrm{z})$ & CE1 $^{a}(\mathrm{eV})$ & MRM2 $(\mathrm{m} / z)$ \\
\hline Bifenthrin & 18.001 & $181.10>166.10$ & 12 & $181.10>153.10$ \\
Permethrin-1 & 19.777 & $183.10>168.10$ & 14 & $183.10>165.10$ \\
Permethrin-2 & 19.902 & $183.10>168.10$ & 14 & $183.10>165.10$ \\
Cypermethrin-1 & 20.630 & $163.10>127.10$ & 6 & $163.10>91.00$ \\
Cypermethrin-2 & 20.733 & $163.10>127.10$ & 6 & $163.10>91.00$ \\
Cypermethrin-3 & 20.793 & $163.10>127.10$ & 6 & $163.10>91.00$ \\
Cypermethrin-4 & 20.831 & $163.10>127.10$ & 6 & $163.10>91.00$ \\
Flucythrinate-1 & 20.794 & $199.10>157.10$ & 10 & $199.10>107.10$ \\
Flucythrinate-2 & 20.985 & $199.10>157.10$ & 10 & $199.10>107.10$
\end{tabular}

${ }^{a}$ CE means collision energy. 

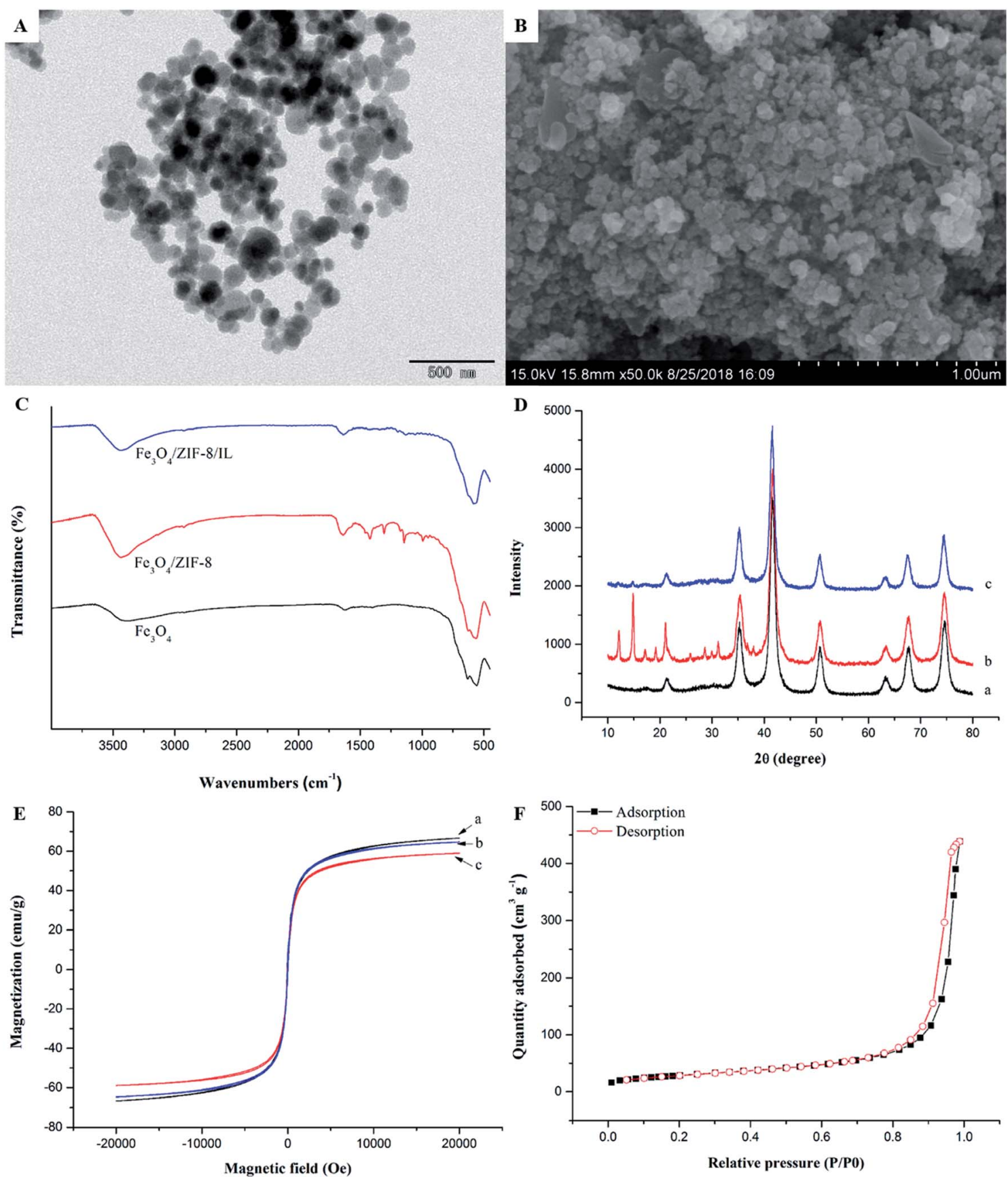

Fig. 1 Characterization of magnetic materials: (A) TEM image and (B) SEM image of $\mathrm{Fe}_{3} \mathrm{O}_{4} / \mathrm{ZIF}-8 / \mathrm{IL}$; (C) FT-IR spectra of magnetic materials; (D) XRD patterns of (a) $\mathrm{Fe}_{3} \mathrm{O}_{4}$, (b) $\mathrm{Fe}_{3} \mathrm{O}_{4} / \mathrm{ZIF}-8$, and (c) $\mathrm{Fe}_{3} \mathrm{O}_{4} / \mathrm{ZIF}-8 / \mathrm{IL}$; (E) magnetic hysteresis loops of (a) $\mathrm{Fe}_{3} \mathrm{O}_{4}$, (b) $\mathrm{Fe}_{3} \mathrm{O}_{4} / \mathrm{ZIF}-8$, and (c) Fe $3 \mathrm{O}_{4} / \mathrm{ZIF}-$ $8 / \mathrm{IL}$; and (F) $\mathrm{N}_{2}$ adsorption-desorption isotherms of $\mathrm{Fe}_{3} \mathrm{O}_{4} / \mathrm{ZIF}-8 / \mathrm{IL}$.

The synthetic magnetic nanocomposite was also characterized by XRD. As shown in Fig. 1D, the crystal structure of ZIF-8 can be confirmed by the characteristic peaks at 10.0, 12.2, 14.9, 17.1, 19.2, 25.8 and $28.5^{\circ}$, and the $\mathrm{Fe}_{3} \mathrm{O}_{4}$ crystal structure contains the typical peaks at $35.3,41.6,50.6,67.7$ and $74.6^{\circ} .^{42}$ Comparison of the XRD patterns of $\mathrm{Fe}_{3} \mathrm{O}_{4} / \mathrm{ZIF}-8$ and $\mathrm{Fe}_{3} \mathrm{O}_{4} / \mathrm{ZIF}-$ $8 / \mathrm{IL}$ revealed that the diffraction peaks of the latter were slightly weaker than those of the former. This observation indicates that $\mathrm{Fe}_{3} \mathrm{O}_{4} / \mathrm{ZIF}-8 / \mathrm{IL}$ exists as an aggregate and is coated with the hydrophobic IL.
The magnetic properties of the synthetic materials were investigated using a vibrating sample magnetometer (Fig. 1E). The saturation magnetization value of $\mathrm{Fe}_{3} \mathrm{O}_{4}$ was $66.7 \mathrm{emu} \mathrm{g}^{-1}$. After the $\mathrm{Fe}_{3} \mathrm{O}_{4}$ nanoparticles were coated with ZIF-8, the saturation magnetization value of $\mathrm{Fe}_{3} \mathrm{O}_{4} / \mathrm{ZIF}-8$ decreased slightly to $64.7 \mathrm{emu}^{-1}$. After modification with the IL, the saturation magnetization value of $\mathrm{Fe}_{3} \mathrm{O}_{4} / \mathrm{ZIF}-8 / \mathrm{IL}$ decreased further to 59.0 $\mathrm{emu}^{-1}$. The magnetic hysteresis loops of the three prepared magnetic materials showed that both their remanence and coercivity values were zero. All of these results suggest that the 

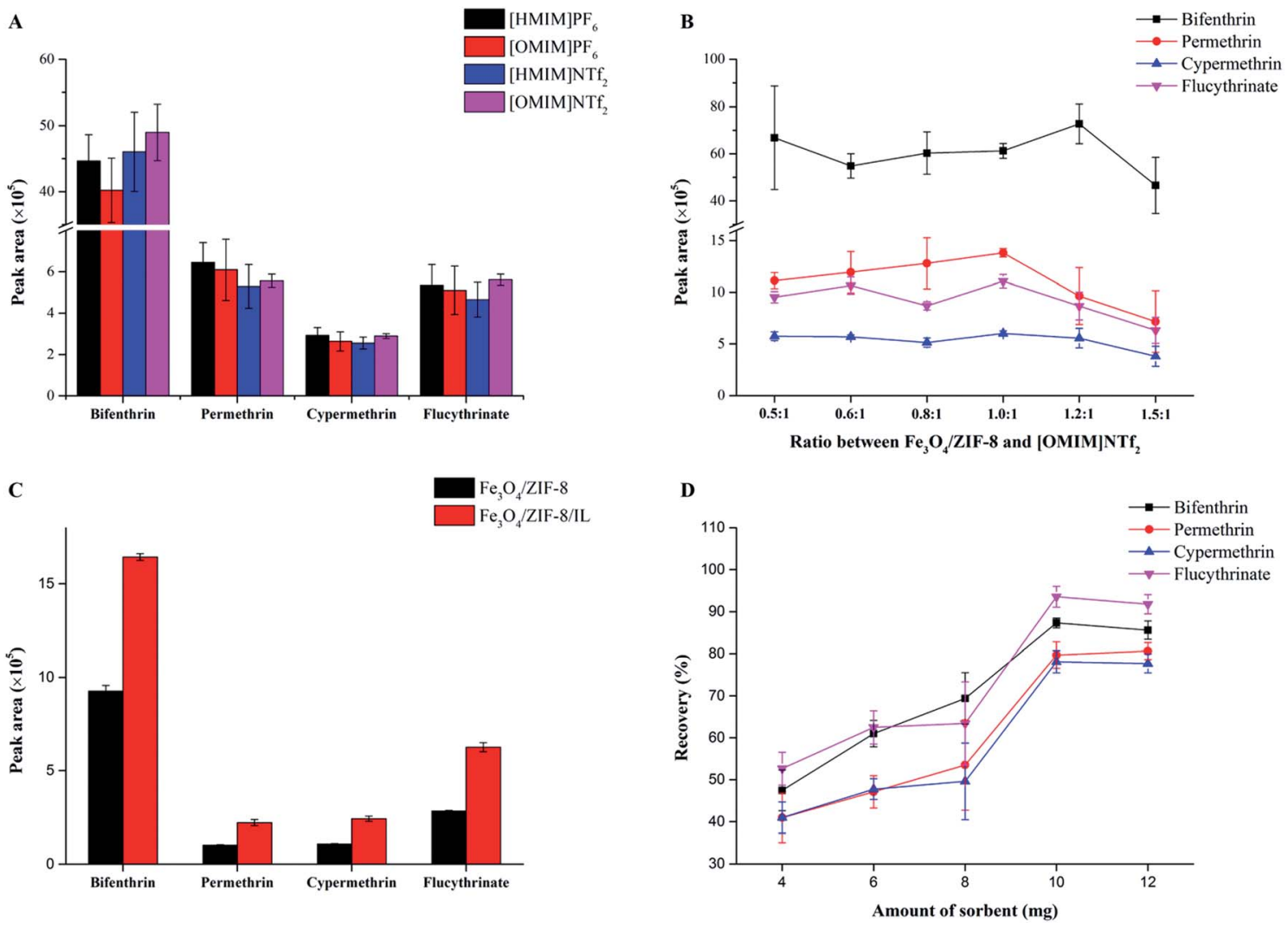

Fig. 2 Effect of (A) different types and (B) different mass ratios of ILs on the $\mathrm{Fe}_{3} \mathrm{O}_{4} / \mathrm{ZIF}-8$; $[\mathrm{HMIM}] \mathrm{PF}$, 1-hexyl-3-methylimidazolium hexafluorophosphate; [OMIM]PF 6 , 1-octyl-3-methylimidazolium hexafluorophosphate; [HMIM]NTf fluoromethanesulfonyl)imide; (C) comparison of $\mathrm{Fe}_{3} \mathrm{O}_{4} / \mathrm{ZIF}-8$ and $\mathrm{Fe}_{3} \mathrm{O}_{4} / \mathrm{ZIF}-8 / \mathrm{IL}$ in the extraction of pyrethroids from ultrapure water; (D) effect of the sorbent mass on the extraction efficiencies of pyrethroids from ultrapure water.

prepared $\mathrm{Fe}_{3} \mathrm{O}_{4} / \mathrm{ZIF}-8 / \mathrm{IL}$ is superparamagnetic and can be rapidly separated by an external magnetic field.

The pore properties of $\mathrm{Fe}_{3} \mathrm{O}_{4} / \mathrm{ZIF}-8 / \mathrm{IL}$ were studied by $\mathrm{N}_{2}$ adsorption measurements at $77 \mathrm{~K}$. As shown by the $\mathrm{N}_{2}$ adsorption-desorption isotherm of $\mathrm{Fe}_{3} \mathrm{O}_{4} / \mathrm{ZIF}-8 / \mathrm{IL}$ in Fig. $1 \mathrm{~F}$, the Brunauer-Emmett-Teller (BET) surface area was $104 \mathrm{~m}^{2} \mathrm{~g}^{-1}$, and the total pore volume was $0.68 \mathrm{~cm}^{3} \mathrm{~g}^{-1}$. The pore size was also calculated by the Barrett-Joyner-Halenda method, and the distribution range was 1.7 to $300 \mathrm{~nm}$, indicating the coexistence of mesopores and macropores. ${ }^{43}$ These results suggest that $\mathrm{Fe}_{3} \mathrm{O}_{4} / \mathrm{ZIF}-8 / \mathrm{IL}$ has a large surface area and pore volume, which are beneficial for facilitating the adsorption of pyrethroids.

\subsection{Optimization of the extraction conditions}

Next, we used single-factor experiments to investigate several experimental conditions affecting the extraction performance of MSPE of pyrethroids. These conditions were the type and content of the IL, type and mass of sorbent, adsorption time, ionic strength, and $\mathrm{pH}$ of the sample solution.

As previously reported, the extraction efficiency of an IL for a pesticide residue depends on the physicochemical characteristics of the IL. ${ }^{39}$ Therefore, selection of an appropriate IL and optimization of its content are essential for optimization of the extraction conditions. In the present work, we studied four ILs, 1hexyl-3-methylimidazolium hexafluorophosphate, 1-hexyl-3- methylimidazolium bis(trifluoromethanesulfonyl)imide, 1-octyl3-methylimidazolium hexafluorophosphate, and [OMIM] $\mathrm{NTf}_{2}$, as potential reagents for modifying $\mathrm{Fe}_{3} \mathrm{O}_{4} / \mathrm{ZIF}-8$. The extraction efficiency was selected to evaluate the effect of modification of $\mathrm{Fe}_{3} \mathrm{O}_{4} / \mathrm{ZIF}-8$ with the four ILs. The extraction efficiencies of the four IL-modified $\mathrm{Fe}_{3} \mathrm{O}_{4} / \mathrm{ZIF}-8$ sorbents for the four pyrethroids were at the same level (Fig. 2A). This result indicates that the length of the alkyl chain of the cation and the type of anion do not greatly affect the extraction efficiencies for the target analytes. However, the results for the [OMIM]NTf ${ }_{2}$ treatment group had the best standard deviations (SDs); hence, [OMIM] $\mathrm{NTf}_{2}$ was adopted as the best IL for $\mathrm{Fe}_{3} \mathrm{O}_{4} / \mathrm{ZIF}-8$ modification. Next, we investigated mass ratios of $\mathrm{Fe}_{3} \mathrm{O}_{4} / \mathrm{ZIF}-8$ to [OMIM] $\mathrm{NTf}_{2}$ of $0.5: 1$, $0.6: 1,0.8: 1,1: 1,1.2: 1$, and $1.5: 1$ to optimize the IL content in $\mathrm{Fe}_{3} \mathrm{O}_{4} / \mathrm{ZIF}-8 / \mathrm{IL}$. A mass ratio of $1: 1$ gave the best extraction efficiencies and SDs (Fig. 2B). Therefore, the mass ratio of $\mathrm{Fe}_{3} \mathrm{O}_{4} /$ ZIF-8 to [OMIM] NTf 2 was set at $1: 1$.

It is well known that adsorbents play a key role in determining extraction efficiency. Consequently, we compared the extraction efficiencies of $\mathrm{Fe}_{3} \mathrm{O}_{4} / \mathrm{ZIF}-8$ with those of $\mathrm{Fe}_{3} \mathrm{O}_{4} / \mathrm{ZIF}-8$ / IL. Compared to $\mathrm{Fe}_{3} \mathrm{O}_{4} / \mathrm{ZIF}-8, \mathrm{Fe}_{3} \mathrm{O}_{4} / \mathrm{ZIF}-8 / \mathrm{IL}$ had better extraction efficiencies for the target analytes (Fig. 2C). This result suggests that modification with $[\mathrm{OMIM}] \mathrm{NTf}_{2}$ can improve the extraction efficiencies of $\mathrm{Fe}_{3} \mathrm{O}_{4} / \mathrm{ZIF}-8$ for pyrethroids. To achieve satisfactory extraction performance with $\mathrm{Fe}_{3} \mathrm{O}_{4} / \mathrm{ZIF}-8 / \mathrm{IL}$ for 
A

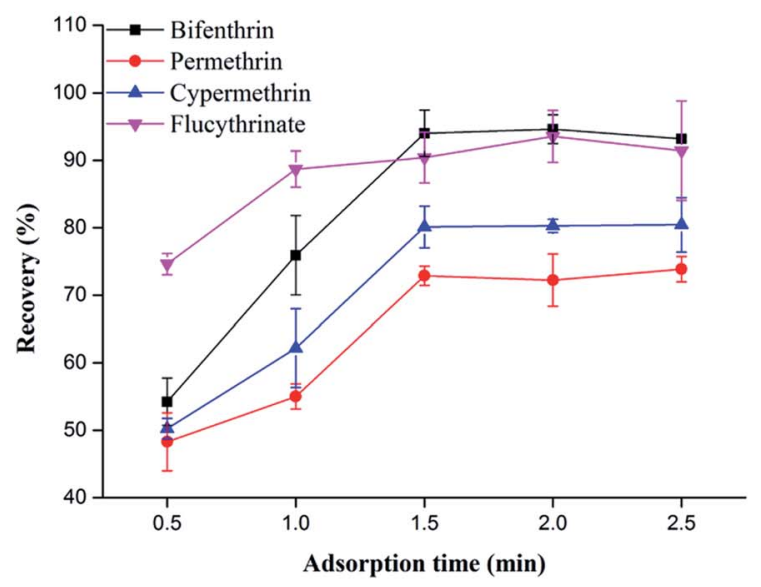

C

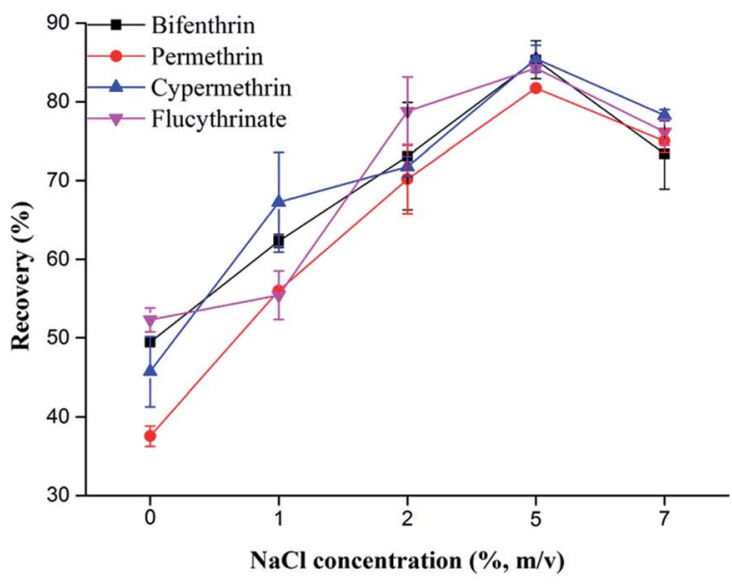

E

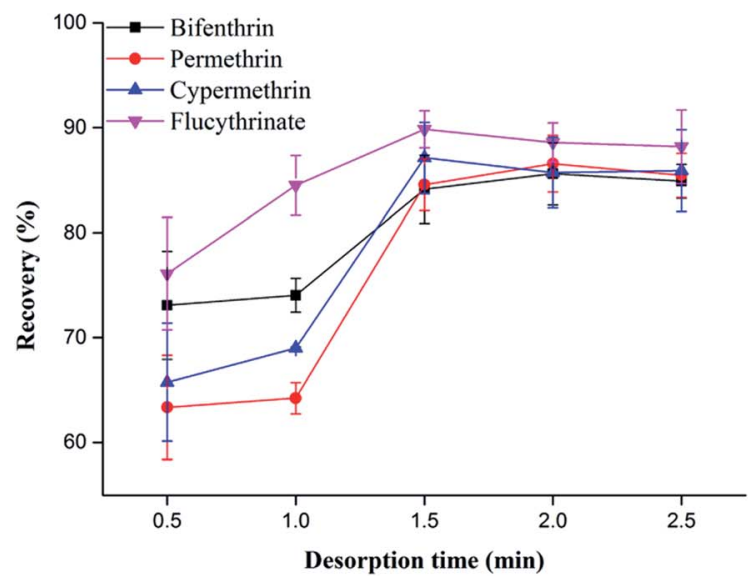

B

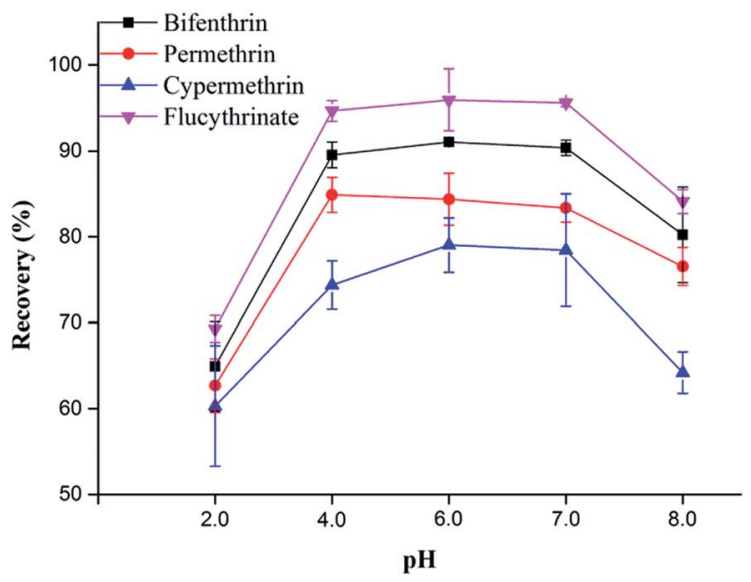

D

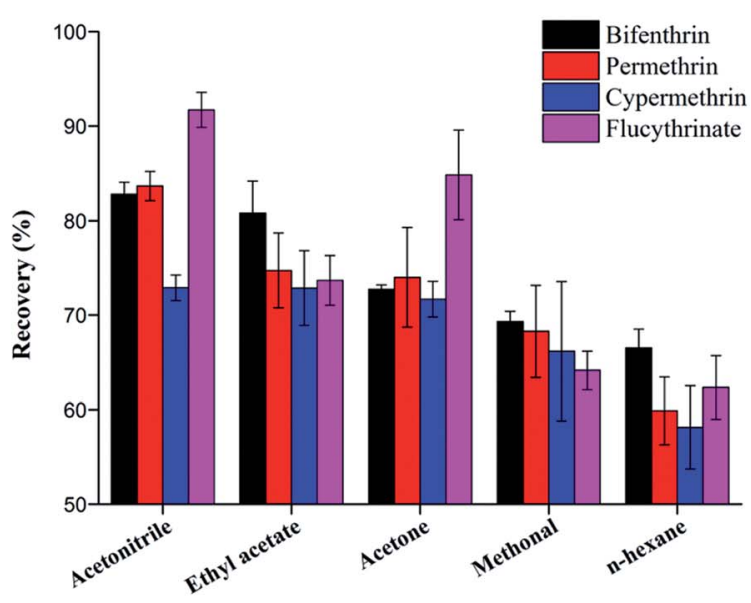

F

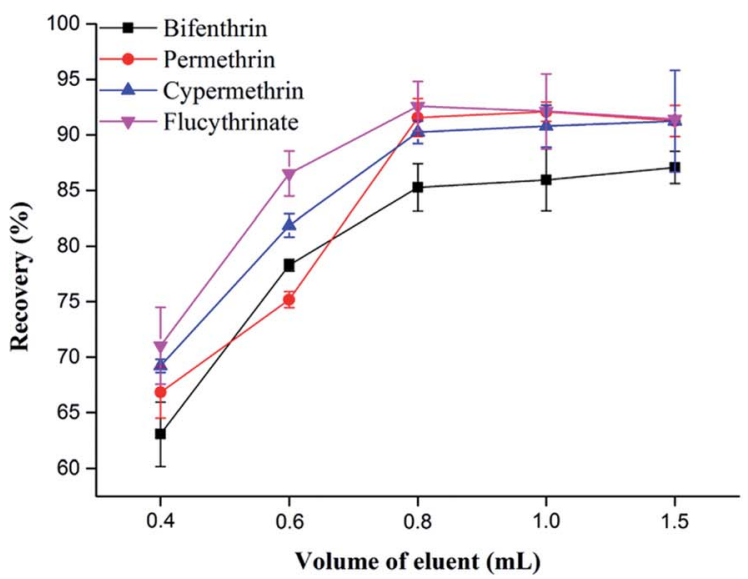

Fig. 3 Effects of different parameters on the MSPE of pyrethroids from ultrapure water: (A) adsorption time, (B) pH of the sample solution, and (C) ionic strength of the sample solution. Desorption conditions: $0.8 \mathrm{~mL}$ of acetonitrile; vortex mixing time, $1.5 \mathrm{~min}$; and the same desorption process was repeated one more time. (D) Desorption solvent, (E) desorption time, and (F) eluent volume. Extraction conditions: amount of adsorbent, $10 \mathrm{mg}$; extraction time, $1.5 \mathrm{~min}$; ionic strength of the sample solution, $5 \% \mathrm{NaCl}$.

pyrethroids, we tested a series of $\mathrm{Fe}_{3} \mathrm{O}_{4} / \mathrm{ZIF}-8 / \mathrm{IL}$ masses ranging from 4 to $12 \mathrm{mg}$ in $10 \mathrm{~mL}$ of sample solution. The extraction efficiency increased as the dose of sorbent was increased from 4 to $10 \mathrm{mg}$ and then remained nearly constant with further increases in the sorbent mass (Fig. 2D). These results show that $10 \mathrm{mg}$ of sorbent is adequate for MSPE of pyrethroids. 
Table 2 Analytical parameters of $\mathrm{Fe}_{3} \mathrm{O}_{4} / \mathrm{ZIF}-8 / \mathrm{IL}$ as an adsorbent for MSPE of the four pyrethroids from ultrapure water samples

\begin{tabular}{|c|c|c|c|c|c|c|}
\hline \multirow[b]{2}{*}{ Pyrethroids } & \multirow[b]{2}{*}{ Regression equation } & \multirow[b]{2}{*}{$\begin{array}{l}\text { Linear range } \\
\left(\mu \mathrm{g} \mathrm{L}^{-1}\right)\end{array}$} & \multirow[b]{2}{*}{$R^{2}$} & \multirow[b]{2}{*}{$\operatorname{LOD}\left(\mu \mathrm{g} \mathrm{L}{ }^{-1}\right)$} & \multicolumn{2}{|c|}{$\operatorname{RSD}^{a}(\%)(n=6)$} \\
\hline & & & & & Intraday & Interday \\
\hline Permethrin & $Y=1.7 \times 10^{7} X+2202$ & $0.5-100$ & 0.9991 & 0.0374 & 2.13 & 7.67 \\
\hline Cypermethrin & $Y=1.4 \times 10^{7} X-9587$ & $0.5-100$ & 0.9998 & 0.0409 & 0.88 & 5.52 \\
\hline Flucythrinate & $Y=4.0 \times 10^{7} X-20766$ & $0.5-100$ & 0.9998 & 0.0367 & 1.24 & 5.53 \\
\hline
\end{tabular}

${ }^{a}$ The RSDs were determined by performing six replicate analyses of samples spiked with each pyrethroid at $10 \mu \mathrm{g} \mathrm{L}$.

The extraction time is a nonnegligible factor that affects the adsorption equilibrium between the adsorbent and sample solution. Thus, $0.5-2.5$ min of vortexing time was set to study the effect of the adsorption time on the MSPE of the analytes. As illustrated in Fig. 3A, the extraction efficiencies for the four pyrethroids increased as the adsorption time was increased from 0.5 to $1.5 \mathrm{~min}$ and then kept relatively constant with further increases in the adsorption time. Based on the above results, $1.5 \mathrm{~min}$ was chosen as the adsorption time for MSPE.

The $\mathrm{pH}$ of the sample solution can affect MSPE performance by altering the surface charge of the adsorbent and/or chemical form of the analyte. In this study, we adjusted the sample solution $\mathrm{pH}$ from 2.0 to 8.0 with $\mathrm{HCl}$ or $\mathrm{NaOH}$ to investigate the effect of $\mathrm{pH}$ on the extraction performance. As shown in Fig. 3B, the extraction efficiencies for analytes remained relatively constant as the sample solution $\mathrm{pH}$ from 4.0 to 7.0 , but decreased with the sample solution $\mathrm{pH}$ adjusted to 2.0 or 8.0. This behaviour was possibly caused by instability of the pyrethroids under highly acidic and alkaline conditions. Because the majority of tea samples are slightly acidic, we did not adjust the $\mathrm{pH}$ values of the tea infusions before extraction. ${ }^{\mathbf{4 4}}$

Salt is another crucial parameter that can affect extraction performance. Therefore, we added $\mathrm{NaCl}(0$ to $7 \%, \mathrm{w} / \mathrm{v})$ to the sample solution to investigate the effect of salt on the extraction efficiencies. As the $\mathrm{NaCl}$ content was increased from 0 to $5 \%$, the extraction efficiencies of the sorbent for the analytes also increased and then decreased with further increases in the $\mathrm{NaCl}$ content (Fig. 3C). Considering the extraction efficiencies and SDs, we selected $5 \%(\mathrm{w} / \mathrm{v}) \mathrm{NaCl}$ as the optimum content for MSPE.

\subsection{Optimization of the desorption conditions}

The desorption procedure is essential for MSPE of pyrethroids. To obtain acceptable desorption performance, we studied the effects of changing the desorption solvent, desorption time, and eluent volume.

It is well known that the desorption solvent can control the extraction efficiency of MSPE. Accordingly, acetonitrile, ethyl acetate, acetone, methanol, and $n$-hexane were chosen as potential desorption solvents. Among these solvents, acetonitrile gave the best extraction efficiencies for the four pyrethroids (Fig. 3D). Moreover, we investigated changes in the desorption time by increasing the vortex mixing time from 0.5 to $2.5 \mathrm{~min}$. A desorption time of $1.5 \mathrm{~min}$ was satisfactory for desorption of pyrethroids from the sorbent (Fig. 3E). Furthermore, the effect of desorption volumes between 0.4 and $1.5 \mathrm{~mL}$ was studied, and we found that $0.8 \mathrm{~mL}$ provided the optimum extraction efficiencies (Fig. 3F). In summary, the optimum process for eluting the pyrethroids used $0.8 \mathrm{~mL}$ of acetonitrile with vortex mixing for $1.5 \mathrm{~min}$ and was repeated one more time.

\subsection{Method validation}

The proposed method was characterized under the optimized conditions for linearity, limit of determination (LOD), and precision in both ultrapure water and a tea infusion, and the results are shown in Tables 2 and 3.

The linearity was determined by analysing ultrapure water and a blank tea infusion sample that were spiked with standard solutions of the pyrethroids at $0.5-500 \mu \mathrm{g} \mathrm{L}^{-1}$ and plotting the peak area versus the concentration. For water sample, good linearities for permethrin, cypermethrin, and flucythrinate over the studied concentration range $\left(0.5-100 \mu \mathrm{g} \mathrm{L}^{-1}\right)$ were observed, with determination coefficients $\left(R^{2}\right)$ in the range of 0.9991-0.9998. For the blank tea sample, good linearities with $R^{2}$ values ranging from 0.9990 to 0.9999 were obtained over the studied concentration range $\left(0.5-500 \mu \mathrm{g} \mathrm{L}^{-1}\right)$ for permethrin, cypermethrin, and

Table 3 Analytical parameters of $\mathrm{Fe}_{3} \mathrm{O}_{4} / \mathrm{ZIF}-8 / \mathrm{IL}$ as an adsorbent for MSPE of the four pyrethroids from tea infusions

\begin{tabular}{|c|c|c|c|c|c|c|}
\hline \multirow[b]{2}{*}{ Pyrethroids } & \multirow[b]{2}{*}{ Regression equation } & \multirow[b]{2}{*}{$\begin{array}{l}\text { Linear range } \\
\left(\mu \mathrm{g} \mathrm{L}^{-1}\right)\end{array}$} & \multirow[b]{2}{*}{$R^{2}$} & \multirow[b]{2}{*}{$\operatorname{LOD}\left(\mu g \mathrm{~L}^{-1}\right)$} & \multicolumn{2}{|c|}{$\mathrm{RSD}^{a}(\%)(n=6)$} \\
\hline & & & & & Intraday & Interday \\
\hline Bifenthrin & $Y=9.3 \times 10^{7} X+23133$ & $0.5-50$ & 0.9997 & 0.0065 & 5.97 & 8.89 \\
\hline Permethrin & $Y=6.0 \times 10^{6} X+11032$ & $0.5-500$ & 0.9999 & 0.0369 & 5.00 & 8.96 \\
\hline Cypermethrin & $Y=4.8 \times 10^{6} X+903$ & $0.5-500$ & 0.9995 & 0.0935 & 9.70 & 11.07 \\
\hline Flucythrinate & $Y=1.4 \times 10^{7} X+420$ & $0.5-500$ & 0.9990 & 0.1017 & 8.90 & 11.95 \\
\hline
\end{tabular}

${ }^{a}$ The RSDs were determined by performing six replicate analyses of samples spiked with each pyrethroid at $10 \mu \mathrm{g} \mathrm{L}^{-1}$. 
Table 4 Comparison of different methods for the analysis of pyrethroids in tea samples

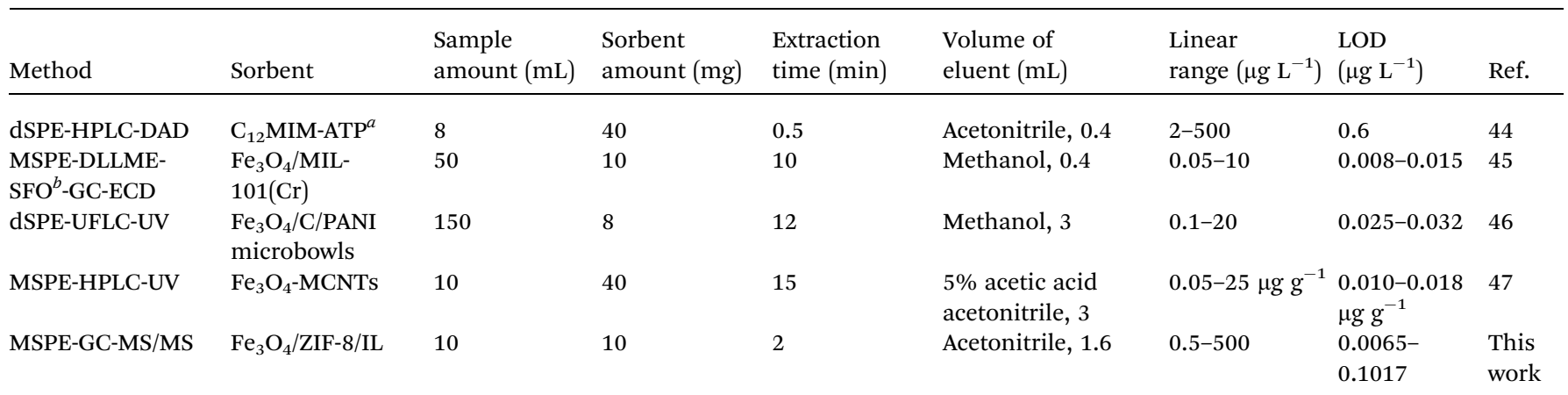

${ }^{a}$ 1-Dodecyl-3-methylimidazolium bromide-attapulgite. ${ }^{b}$ Solidification of a floating organic drop.

flucythrinate. However, the response to bifenthrin were far higher than those to the other three pyrethroids and were saturated for the ultrapure water sample spiked at $100 \mu \mathrm{g} \mathrm{\textrm {L } ^ { - 1 }}$ and for the tea infusion sample spiked at $200 \mu \mathrm{g} \mathrm{\textrm {L } ^ { - 1 }}$. Consequently, the linear ranges for bifenthrin in ultrapure water sample $\left(0.5-50 \mu \mathrm{g} \mathrm{L}^{-1}\right)$ and tea infusion sample $\left(0.5-50 \mu \mathrm{g} \mathrm{L}^{-1}\right)$ were smaller than that for the other three pyrethroids and had $R^{2}$ values of 0.9991 and 0.9997 , respectively. The LODs, calculated using $\mathrm{S} / \mathrm{N}$ ratios of three, were $0.0040-0.0409 \mu \mathrm{g} \mathrm{L}^{-1}$ in water and 0.0065-0.1017 $\mu \mathrm{g} \mathrm{L}^{-1}$ in the tea infusion. The method precision was evaluated by measuring the RSDs for samples spiked with the standard solution at $10 \mu \mathrm{g} \mathrm{L}^{-1}$. Six replicates were analysed for each experiment. For the water sample, the intra- and inter-day RSDs for the precision were in the range of $0.69-2.13 \%$ and $4.26-7.27 \%$, respectively. For the tea infusion, the intra- and inter-day RSDs for the precision were in the range of $5.00-9.70 \%$ and $8.89-11.95 \%$, respectively. These results indicate that the suggested method possesses high sensitivity, a wide linear range, and good repeatability.

\subsection{Comparison of the $\mathrm{Fe}_{3} \mathrm{O}_{4} / \mathrm{ZIF}-8 / \mathrm{IL}$-based method with other reported methods}

We compared our $\mathrm{Fe}_{3} \mathrm{O}_{4} / \mathrm{ZIF}$-8/IL-based method with several other methods for the determination of pyrethroids in tea samples (Table 4). Compared with dispersive SPE, the proposed $\mathrm{Fe}_{3} \mathrm{O}_{4} / \mathrm{ZIF}$-8/IL-based method does not require a timeconsuming centrifugation step, which makes it more convenient. Moreover, the extraction time of the developed method is shorter than that of any other MSPE-based method. Regarding analytical performance, our method exhibits the widest linear range and lowest LOD among the available methods. Based on our comparison, we can conclude that our proposed $\mathrm{Fe}_{3} \mathrm{O}_{4} / \mathrm{ZIF}$ 8/IL-MSPE method is a sensitive and simple technique for the analysis of four pyrethroid insecticides in tea infusions.

\subsection{Real sample analysis}

We applied the proposed $\mathrm{Fe}_{3} \mathrm{O}_{4} / \mathrm{ZIF}-8 /$ IL-based MSPE method to the analysis of four pyrethroid insecticides in infusions of $\mathrm{Pu}$ -

Table 5 Analytical results for the determination of pyrethroids in infusions of real tea samples

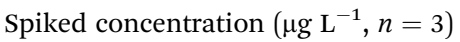

$\underline{0} \quad \underline{10} \quad \underline{50}$

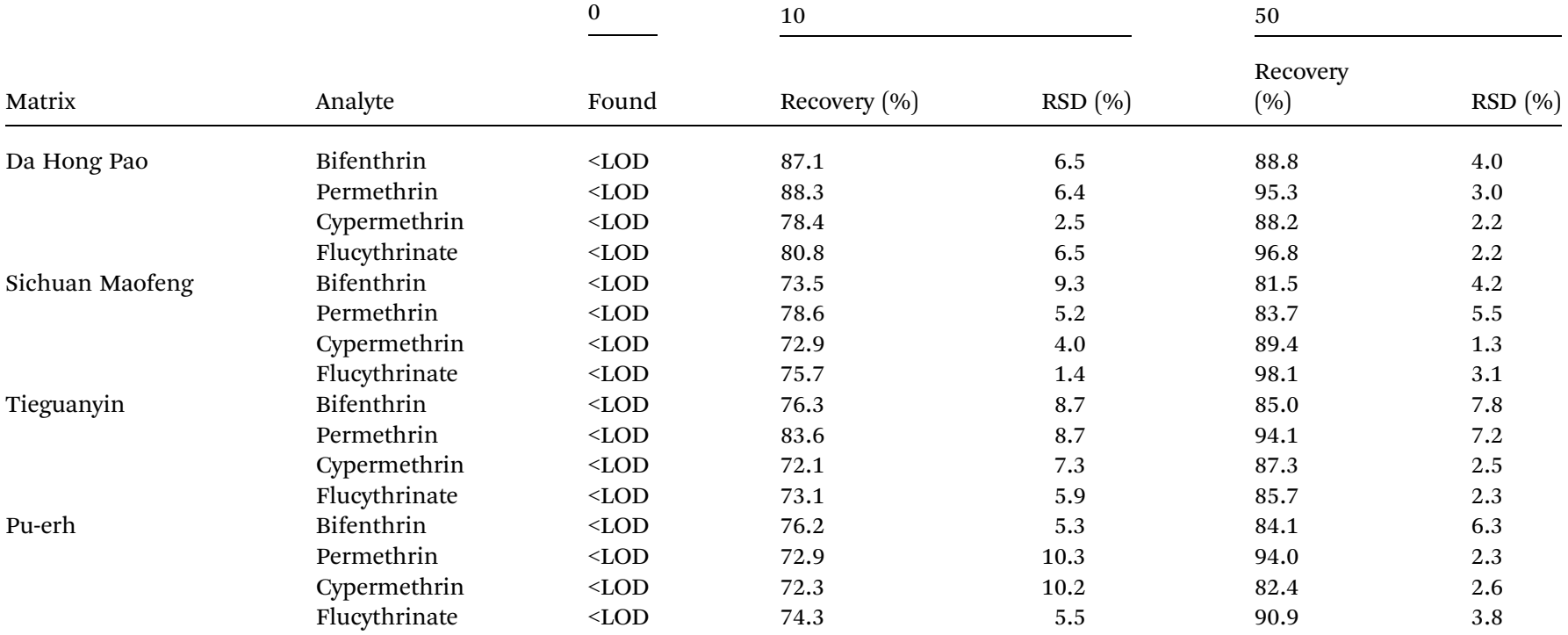



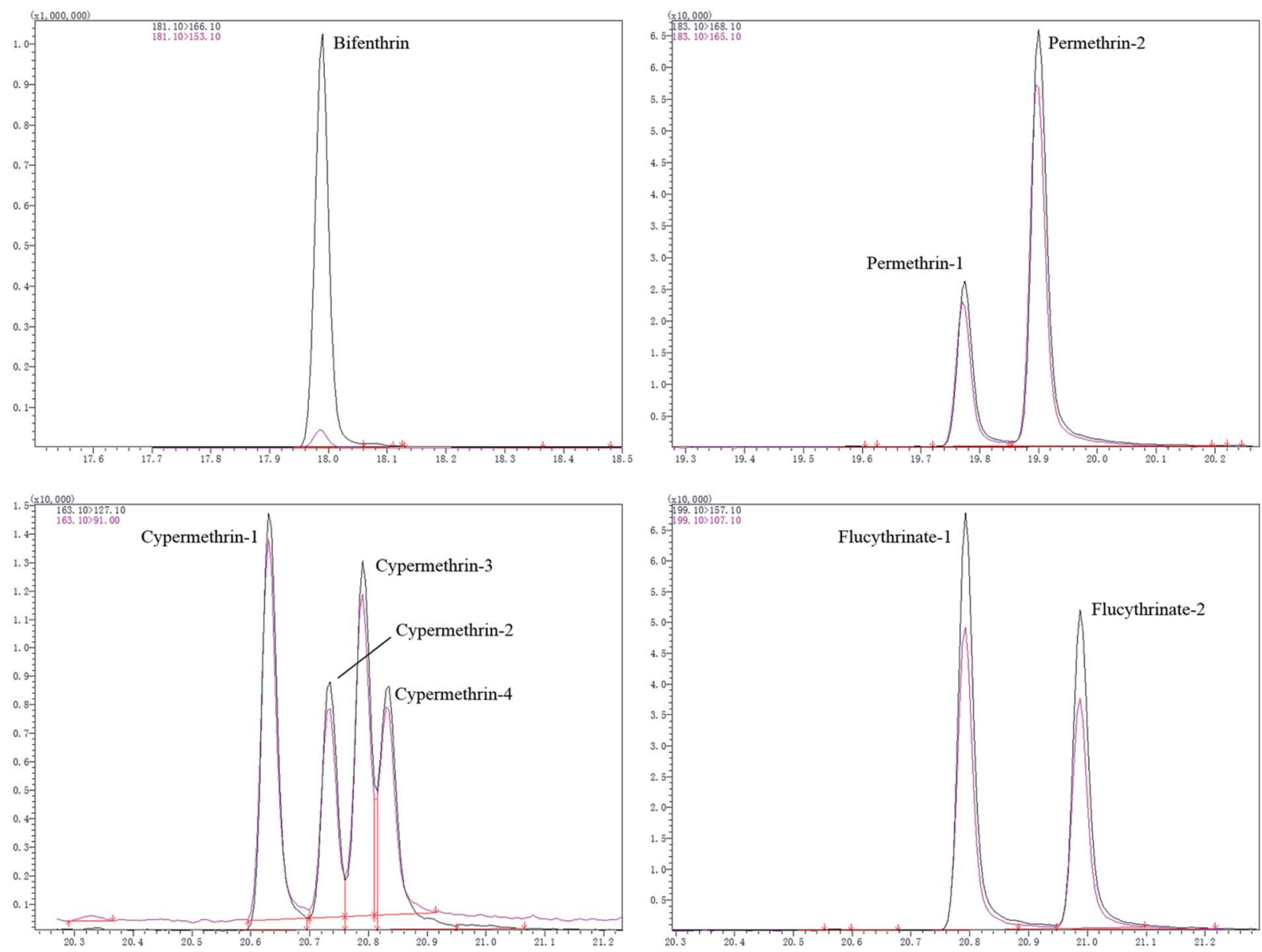

Fig. 4 Extracted total ion chromatograms obtained by the proposed method for pyrethroids from a real tea sample (Sichuan Maofeng) spiked at $10 \mu \mathrm{g} \mathrm{L}^{-1}$

erh, Tieguanyin, Da Hong Pao, and Sichuan Maofeng teas. The method showed good accuracy (recovery), precision (RSD), and utility for the determination of the pyrethroid insecticides in the tea infusions (Table 5). No pyrethroids were found in the four tea infusions. The extracted total ion chromatograms of pyrethroids obtained from the Sichuan Maofeng tea after spiking at $10 \mu \mathrm{g} \mathrm{L}^{-1}$ are shown in Fig. 4.

\section{Conclusions}

In this study, a novel magnetic adsorbent was prepared by immobilizing [OMIM] $\mathrm{NTf}_{2}$ on the surface of $\mathrm{Fe}_{3} \mathrm{O}_{4} / \mathrm{ZIF}-8$ via a simple direct immersion method based on the "physisorption" mechanism. The obtained magnetic nanocomposite possessed high magnetism, a satisfactory BET surface area, and a large pore volume. Combined with GC-MS/MS, the adsorbent was first employed as an adsorbent for MSPE of pyrethroid insecticides from tea infusions. Under the optimized conditions, the $\mathrm{Fe}_{3} \mathrm{O}_{4} / \mathrm{ZIF}$-8/IL-based method offers a wide linear range, excellent sensitivity, good accuracy, and good precision. Modification promoted the adsorption of pyrethroids by $\mathrm{Fe}_{3} \mathrm{O}_{4}$ / ZIF-8/IL and gave satisfactory MSPE performance for pyrethroids in tea infusions. The development of $\mathrm{Fe}_{3} \mathrm{O}_{4} / \mathrm{ZIF}-8 / \mathrm{IL}-$
MSPE could be extended to other IL-modified MOFs for the enrichment and determination of many other organic pollutants or pesticide residues in beverages.

\section{Conflicts of interest}

There are no conflicts to declare.

\section{Acknowledgements}

This work was supported by the National Key Research Development Program of China (grant number 2016YFD0200205), the Agricultural Science and Technology Innovation Program of CAAS (grant number CAAS-XTCX2019024), and the Risk Assessment on Vegetable Products (GJFP2019002).

\section{References}

1 T. Karak and R. M. Bhagat, Food Res. Int., 2010, 43, 22342252.

2 M. Saleem, V. M. Adhami, I. A. Siddiqui and H. Mukhtar, Nutr. Cancer, 2003, 47, 13-23.

3 K.-W. Ng, Z.-J. Cao, H.-B. Chen, Z.-Z. Zhao, L. Zhu and T. Yi, Crit. Rev. Food Sci. Nutr., 2018, 58, 2957-2980. 
4 H. Li, F. Cheng, Y. Wei, M. J. Lydy and J. You, J. Hazard. Mater., 2017, 324, 258-271.

5 W. Tang, D. Wang, J. Wang, Z. Wu, L. Li, M. Huang, S. Xu and D. Yan, Chemosphere, 2018, 191, 990-1007.

6 W. Deng, L. Yu, X. Li, J. Chen, X. Wang, Z. Deng and Y. Xiao, Food Chem., 2019, 274, 891-899.

7 Y. Fang, W. Tian, F. Pei, P. Li, X. Shao, Y. Fan and Q. Hu, Food Chem., 2017, 229, 347-353.

8 H. Qian, L. Hu, C. Liu, H. Wang, H. Gao and W. Zhou, J. Chromatogr. A, 2018, 1559, 86-94.

9 V. Nardelli, F. Casamassima, G. Gesualdo, D. Li, W. M. V. Marchesiello, D. Nardiello and M. Quinto, J. Agric. Food Chem., 2018, 66, 10267-10273.

10 S. Zhang, Q. Yang, W. Wang, C. Wang and Z. Wang, J. Agric. Food Chem., 2016, 64, 2792-2801.

11 H. Dong, K. Xiao, Y. Xian, Y. Wu and L. Zhu, Food Chem., 2019, 270, 196-203.

12 N. Li, H.-L. Jiang, X. Wang, X. Wang, G. Xu, B. Zhang, L. Wang, R.-S. Zhao and J.-M. Lin, TrAC, Trends Anal. Chem., 2018, 102, 60-74.

13 C. Herrero-Latorre, J. Barciela-García, S. García-Martín, R. M. Peña-Crecente and J. Otárola-Jiménez, Anal. Chim. Acta, 2015, 892, 10-26.

14 M. Hemmati, M. Rajabi and A. Asghari, Microchim. Acta, 2018, 185, 160.

15 F. Maya, C. Palomino Cabello, R. M. Frizzarin, J. M. Estela, G. Turnes Palomino and V. Cerdà, TrAC, Trends Anal. Chem., 2017, 90, 142-152.

16 C. L. Hobday, T. D. Bennett, D. Fairen-Jimenez, A. J. Graham, C. A. Morrison, D. R. Allan, T. Düren and S. A. Moggach, J. Am. Chem. Soc., 2018, 140, 382-387.

17 F. Afsahi, H. Vinh-Thang, S. Mikhailenko and S. Kaliaguine, J. Power Sources, 2013, 239, 415-423.

18 Q. Zhou, L. Zhu, X. Xia and H. Tang, Microchim. Acta, 2016, 183, 1839-1846.

19 J. Yang, Y.-B. Zhang, Q. Liu, C. A. Trickett, E. GutiérrezPuebla, M. Á. Monge, H. Cong, A. Aldossary, H. Deng and O. M. Yaghi, J. Am. Chem. Soc., 2017, 139, 6448-6455.

20 M. Zhang, G. Feng, Z. Song, Y.-P. Zhou, H.-Y. Chao, D. Yuan, T. T. Y. Tan, Z. Guo, Z. Hu, B. Z. Tang, B. Liu and D. Zhao, J. Am. Chem. Soc., 2014, 136, 7241-7244.

21 K. Manna, T. Zhang and W. Lin, J. Am. Chem. Soc., 2014, 136, 6566-6569.

22 B. Chen, Z. Yang, Y. Zhu and Y. Xia, J. Mater. Chem., 2014, 2, 16811-16831.

23 H. Bux, F. Liang, Y. Li, J. Cravillon, M. Wiebcke and J. Caro, J. Am. Chem. Soc., 2009, 131, 16000-16001.

24 J. Yao, R. Chen, K. Wang and H. Wang, Microporous Mesoporous Mater., 2013, 165, 200-204.
25 Z. Wang, B. Zhang, C. Ye and L. Chen, Hydrometallurgy, 2018, 180, 262-270.

26 W. Zhang, Y. Ying, J. Ma, X. Guo, H. Huang, D. Liu and C. Zhong, J. Membr. Sci., 2017, 527, 8-17.

27 X. Lian, Y. Fang, E. Joseph, Q. Wang, J. Li, S. Banerjee, C. Lollar, X. Wang and H.-C. Zhou, Chem. Soc. Rev., 2017, 46, 3386-3401.

28 Z. Lei, B. Chen, Y.-M. Koo and D. R. MacFarlane, Chem. Rev., 2017, 117, 6633-6635.

29 Y. Zhou and J. Qu, ACS Appl. Mater. Interfaces, 2017, 9, 32093222.

30 R. L. Vekariya, J. Mol. Liq., 2017, 227, 44-60.

31 A. Berthod, M. J. Ruiz-Ángel and S. Carda-Broch, J. Chromatogr. A, 2018, 1559, 2-16.

32 S. P. M. Ventura, F. A. e. Silva, M. V. Quental, D. Mondal, M. G. Freire and J. A. P. Coutinho, Chem. Rev., 2017, 117, 6984-7052.

33 M. J. Salar-García, V. M. Ortiz-Martínez, F. J. HernándezFernández, A. P. de los Ríos and J. Quesada-Medina, J. Hazard. Mater., 2017, 321, 484-499.

34 B. H. Fumes, M. R. Silva, F. N. Andrade, C. E. D. Nazario and F. M. Lanças, TrAC, Trends Anal. Chem., 2015, 71, 9-25.

35 X. Wei, Y. Wang, J. Chen, P. Xu and Y. Zhou, Talanta, 2018, 182, 484-491.

36 G. Liu, L. Li, X. Huang, S. Zheng, D. Xu, X. Xu, Y. Zhang and H. Lin, Microporous Mesoporous Mater., 2018, 270, 258-264.

37 C.-F. Zhang, L.-G. Qiu, F. Ke, Y.-J. Zhu, Y.-P. Yuan, G.-S. Xu and X. Jiang, J. Mater. Chem. A, 2013, 1, 14329-14334.

38 M. Yang, X. Wu, X. Xi, P. Zhang, X. Yang, R. Lu, W. Zhou, S. Zhang, H. Gao and J. Li, Food Chem., 2016, 197, 1064-1072.

39 M. Yang, Y. Gu, X. Wu, X. Xi, X. Yang, W. Zhou, H. Zeng, S. Zhang, R. Lu, H. Gao and J. Li, Food Chem., 2018, 239, 797-805.

40 S. Zhang, W. Yao, J. Ying and H. Zhao, J. Chromatogr. A, 2016, 1452, 18-26.

41 G. Liu, L. Li, D. Xu, X. Huang, X. Xu, S. Zheng, Y. Zhang and H. Lin, Carbohydr. Polym., 2017, 175, 584-591.

42 X. Huang, Y. Liu, G. Liu, L. Li, X. Xu, S. Zheng, D. Xu and H. Gao, RSC Adv., 2018, 8, 25351-25360.

43 Q. Wu, S. Cheng, C. Wang, X. Li, Z. Li and C. Hao, Microchim. Acta, 2016, 183, 3009-3017.

44 X. Yang, X. Lin, Y. Mi, H. Gao, J. Li, S. Zhang, W. Zhou and R. Lu, J. Chromatogr. B: Anal. Technol. Biomed. Life Sci., 2018, 1089, 70-77.

45 N. Lu, X. He, T. Wang, S. Liu and X. Hou, Microchem. J., 2018, 137, 449-455.

46 Y. Wang, Y. Sun, Y. Gao, B. Xu, Q. Wu, H. Zhang and D. Song, Talanta, 2014, 119, 268-275.

47 L. Gao and L. Chen, Microchim. Acta, 2013, 180, 423-430. 